\title{
Mortars with CDW Recycled Aggregates Submitted to High Levels of $\mathrm{CO}_{2}$
}

\author{
Ricardo Infante Gomes ${ }^{1, *}$, David Bastos ${ }^{1}$, Catarina Brazão Farinha ${ }^{1}$, Cinthia Maia Pederneiras ${ }^{1}$, \\ Rosário Veiga $^{2}\left(\mathbb{D}\right.$, Jorge de Brito ${ }^{3}(\mathbb{D})$, Paulina Faria ${ }^{3,4}(\mathbb{D})$ and António Santos Silva ${ }^{2}$ \\ 1 c5Lab-Sustainable Construction Materials Association, Edifício Central Park, Rua Central Park 6, \\ 2795-242 Linda-a-Velha, Portugal; dbastos@c5lab.pt (D.B.); cfarinha@c5lab.pt (C.B.F.); \\ cpederneiras@c5lab.pt (C.M.P.) \\ 2 National Laboratory for Civil Engineering, Av. do Brasil 101, 1700-066 Lisbon, Portugal; rveiga@lnec.pt (R.V.); \\ ssilva@lnec.pt (A.S.S.) \\ 3 CERIS, Instituto Superior Técnico, University of Lisbon, Av. Rovisco Pais 1, 1049-001 Lisbon, Portugal; \\ jb@civil.ist.utl.pt (J.d.B.); paulina.faria@fct.unl.pt (P.F.) \\ 4 NOVA School of Science and Technology, NOVA University of Lisbon, 2829-516 Caparica, Portugal \\ * Correspondence: rgomes@c5lab.pt
}

Citation: Infante Gomes, R.; Bastos, D.; Brazão Farinha, C.; Pederneiras, C.M.; Veiga, R.; de Brito, J.; Faria, P.; Santos Silva, A. Mortars with CDW Recycled Aggregates Submitted to High Levels of $\mathrm{CO}_{2}$. Infrastructures 2021, 6, 159. https://doi.org/ $10.3390 /$ infrastructures6110159

Academic Editor: Moncef L. Nehdi

Received: 23 September 2021

Accepted: 3 November 2021

Published: 5 November 2021

Publisher's Note: MDPI stays neutral with regard to jurisdictional claims in published maps and institutional affiliations.

Copyright: (c) 2021 by the authors Licensee MDPI, Basel, Switzerland. This article is an open access article distributed under the terms and conditions of the Creative Commons Attribution (CC BY) license (https:// creativecommons.org/licenses/by/ $4.0 /)$.

\begin{abstract}
Construction and demolition wastes (CDW) are generated at a large scale and have a diversified potential in the construction sector. The replacement of natural aggregates (NA) with CDW recycled aggregates (RA) in construction materials, such as mortars, has several environmental benefits, such as the reduction in the natural resources used in these products and simultaneous prevention of waste landfill. Complementarily, $\mathrm{CDW}$ have the potential to capture $\mathrm{CO}_{2}$ since some of their components may carbonate, which also contributes to a decrease in global warming potential. The main objective of this research is to evaluate the influence of the exposure of CDW RA to $\mathrm{CO}_{2}$ produced in cement factories and its effect on mortars. Several mortars were developed with a volumetric ratio of 1:4 (cement: aggregate), with NA (reference mortar), CDW RA and CDW RA exposed to high levels of $\mathrm{CO}_{2}$ (CRA). The two types of waste aggregate were incorporated, replacing NA at $50 \%$ and $100 \%$ (in volume). The mortars with NA and non-carbonated RA and CRA from $\mathrm{CDW}$ were analysed, accounting for their performance in the fresh and hardened states in terms of workability, mechanical behaviour and water absorption by capillarity. It was concluded that mortars with CDW (both CRA and non-carbonated RA) generally present a good performance for non-structural purposes, although they suffer a moderate decrease in mechanical performance when NA is replaced with RA. Additionally, small improvements were found in the performance of the aggregates and mortars with CRA subjected to $\mathrm{C} \mathrm{CO}_{2}$ curing for a short period ( $5 \mathrm{~h}$ ), while a long carbonation period ( $5 \mathrm{~d}$ ) led to a decrease in performance, contrary to the results obtained in the literature that indicate a significant increase in such characteristics. This difference could be because the literature focused on made-in-laboratory CDW aggregates, while, in this research, the wastes came from real demolition activities, and were thus older and more heterogeneous.
\end{abstract}

Keywords: construction and demolition waste; rendering mortar; sustainable mortar; cement; carbon capture and storage; recycled aggregate

\section{Introduction}

In recent years, the concentration of carbon dioxide $\left(\mathrm{CO}_{2}\right)$ in the atmosphere has exponentially increased. It is estimated that $40 \%$ of this increase is due to human activities [1]. The high concentration of this gas, as well as the other greenhouse gases, is responsible for the phenomenon known as global warming. This is one of the main global threats and measures to combat it are urgently required.

According to the European Commission, from 25\% to 30\% of the waste generated in Europe comes from the construction industry, construction and demolition waste (CDW), 
which is available in large quantities at low acquisition costs [1,2]. Their incorporation in construction products, such as mortars and concrete, as recycled aggregates (RA), has a positive impact, reducing the exploitation of natural resources in the natural aggregates industry while improving the lifecycle of these products.

The cement industry is responsible for the production of one of the most-used materials in the construction sector. It is estimated to be responsible for the emission of from approximately 650 to $800 \mathrm{~kg}$ of $\mathrm{CO}_{2}$ for each tonne of cement produced [3]. This makes this industry one of the most polluting in terms of $\mathrm{CO}_{2}$ emissions. Nevertheless, these emissions occur throughout the cement manufacturing process-from the extraction of raw materials, namely from finite and scarce natural resources, to shipping. Thus, there is an exponential consumption of these resources and corresponding repercussions for the environment, which has been the target of changes and measures taken by the construction sector.

In cementitious mortars, cement acts as a binder and undergoes carbonation, a reaction in which free lime reacts with $\mathrm{CO}_{2}$ to form calcium carbonate $\left(\mathrm{CaCO}_{3}\right)$. Besides free lime, other hydrated cementitious products can react with $\mathrm{CO}_{2}$ [4]. Thus, any cementitious material is able to capture part of the $\mathrm{CO}_{2}$ emitted during cement production [1].

The use of CDW as an RA in mortars and concrete has been the object of several studies, with promising results. However, generally, these aggregates reduce the performance of these materials. Several studies [5-9] claim that the incorporation of CDW aggregates subjected to forced carbonation in mortars and concrete (CRA) improves their characteristics compared to non-carbonated aggregates, while the latter contribute to the capture and storage of $\mathrm{CO}_{2}$ (carbon capture and storage (CCS)).

It should be noted that, in the mentioned studies [5-9], waste formulated in a laboratory or consisting only of cementitious matrix materials is used. However, the present study aims to incorporate RA from treatment and recycling plants. This study integrates project WP10B, forced and accelerated sequestration of $\mathrm{CO}_{2}$ by $\mathrm{CDW}$ to incorporate as aggregates in mortars and concrete, from the Sustainable Construction Materials Association collaborative laboratory $\left({ }^{5} \mathrm{Lab}\right)$, which intends to optimise $\mathrm{CO}_{2}$ capture through $\mathrm{CDW}$ for subsequent incorporation as aggregates in mortars and concrete, offsetting part of the $\mathrm{CO}_{2}$ emitted by the cement industry.

This paper presents the results of the evaluation of the performance of mortars formulated with an RA of CDW subjected to forced and accelerated carbonation over both a short and a long period of time: $5 \mathrm{~h}$ (CRA-5h) and 5 days (CRA-5d).

\section{Materials and Methods}

\subsection{Materials}

A CDW commercialized by a Portuguese treatment and recycling plant (Figure 1) was incorporated into cementitious mortars, at replacement contents of $50 \%$ and $100 \%$. This waste, referred to as CDW-A, corresponds to a mixture of particles with dimensions below $2 \mathrm{~mm}$ (Figure 2). This waste was previously characterized, as W1, by Infante Gomes et al. [10].

Mixtures of recycled aggregates are heterogeneous in terms of their composition. Therefore, to understand which constituents make up the CDW-A mix, these were classified according to the European standards EN 933-11 [11] and EN 13242 [12]. The waste constituents are then separated and classified into categories such as: concrete, concrete products, mortar and concrete masonry units (Rc); unbound aggregates, natural stone and hydraulically bound aggregates $(\mathrm{Ru})$; glass $(\mathrm{Rg})$; clay masonry units $(\mathrm{Rb})$; bituminous materials $(\mathrm{Ra})$ and other materials, including cohesive, metals, plastic, rubber, non-floating wood and gypsum plaster (X), as in Figure 3. Rc is the major component in the CDW-A mixture, with an amount of about $42 \%$, as stated in Figure 3 . 


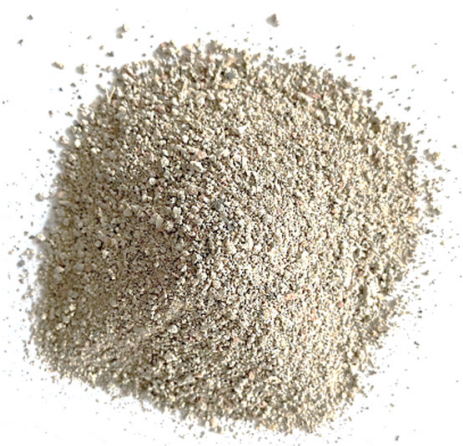

Figure 1. CDW-A, commercialized by a Portuguese treatment and recycling plant.

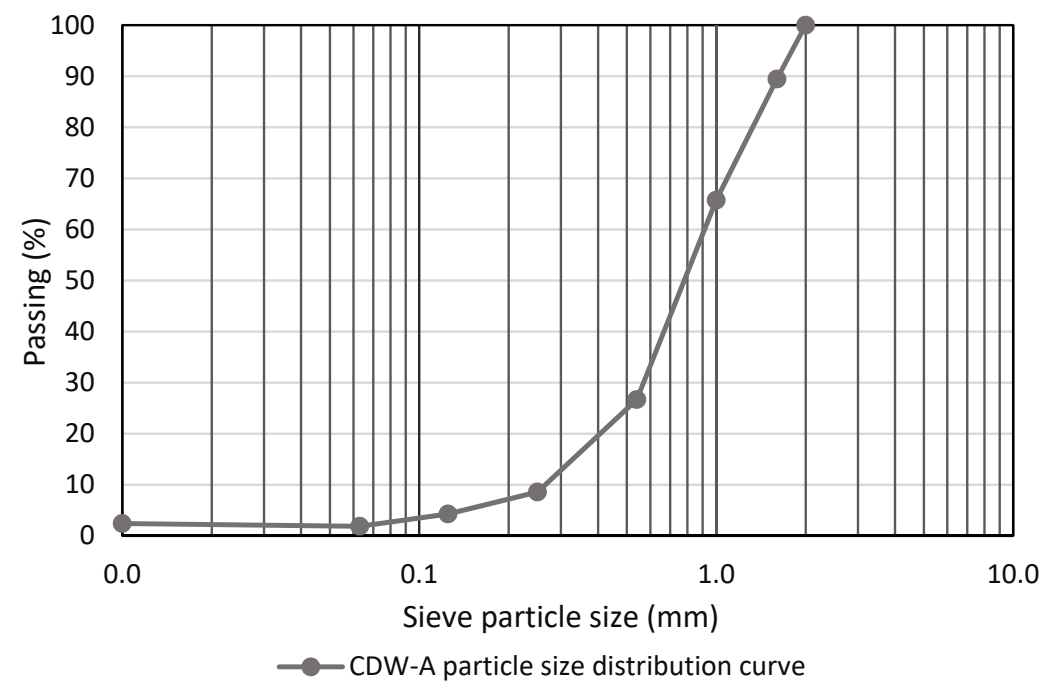

Figure 2. Particle size distribution of CDW-A.

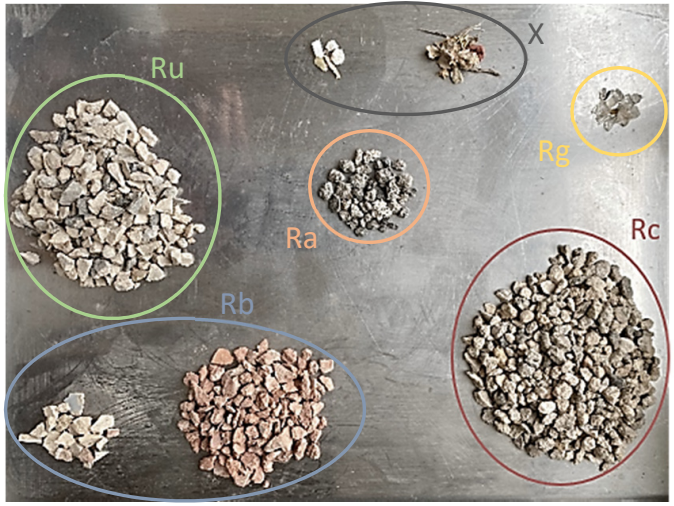

(a)

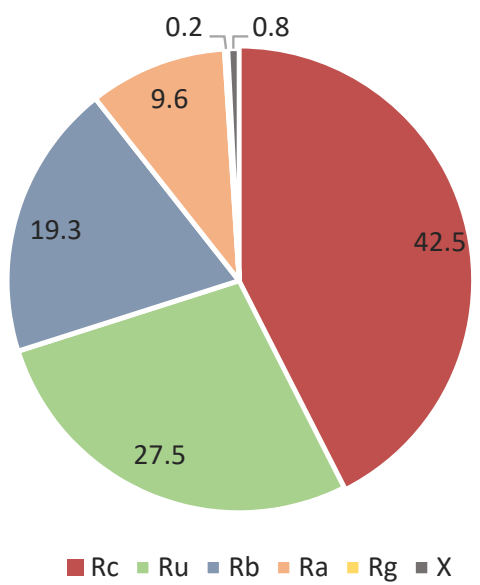

(b)

Figure 3. (a) CDW-A separation into its constituents and (b) classification of CDW-A constituents: concrete, concrete products, mortar and concrete masonry units (Rc); unbound aggregates, natural stone and hydraulically bound aggregates $(\mathrm{Ru})$; clay masonry units $(\mathrm{Rb})$; bituminous materials $(\mathrm{Ra})$; glass $(\mathrm{Rg})$; other materials, including cohesive, metals, plastic, rubber, non-floating wood and gypsum plaster $(X)$.

CDW-A in cementitious mortars was incorporated in its natural state (non-carbonated) and subjected to forced carbonation in a chamber, at $23{ }^{\circ} \mathrm{C}, 60 \%$ of relative humidity and 
$25 \%$ of $\mathrm{CO}_{2}$, for $5 \mathrm{~h}$ or 5 days. The binder used to prepare the mortars was Portland cement type CEM II/B-L $32.5 \mathrm{~N}$, from the Portuguese cement company CIMPOR. The natural aggregate (NA) used was a combination of several calibrated siliceous sands. composed of over $98 \%$ silica, with quartzite, quartz and feldspar minerals, from Areipor-Areias Portuguesas. The binder:aggregate volumetric ratio used for these non-structural mortars was 1:4.

The grain size distribution curve of NA was adjusted to the one of CDW-A, to obtain comparable aggregates from this perspective. CDW-A presented a grain size curve considered suitable for mortar formulation; therefore, the feasibility of its direct use in the industry is an advantage that should be taken into account. Hence, the exact curve of this RA was used. Seven types of mortar were formulated. Of these, the reference mortar is the only one that does not contain RA, being composed of $100 \%$ NA. Two mortars were studied, with non-carbonated recycled waste with substitution ratios of 50\% (A-50\%) and $100 \%$ (A-100\%). Mortars with the same replacement ratios of NA with RA were tested, with the recycled aggregates subjected to forced and accelerated carbonation for a period of $5 \mathrm{~h}$ (AC- $5 \mathrm{~h}-50 \%$ and AC- $5 \mathrm{~h}-100 \%$ ) and a period of 5 days (AC- $5 \mathrm{~d}-50 \%$ and AC- $5 \mathrm{~d}-100 \%$ ), see Table 1.

Table 1. Mortars' composition (in volume, for $1 \mathrm{dm}^{3}$ ).

\begin{tabular}{cccccc}
\hline Mortar & NA & RA & CRA-5h & CRA-5d & Cement \\
\hline REF-A & 0.8 & - & - & - & 0.2 \\
A-50\% & 0.4 & 0.4 & - & - & 0.2 \\
AC-5h-50\% & 0.4 & - & 0.4 & - & 0.2 \\
AC-5d-50\% & 0.4 & - & - & 0.4 & 0.2 \\
A-100\% & - & 0.8 & - & - & 0.2 \\
AC-5h-100\% & - & - & 0.8 & - & 0.2 \\
AC-5d-100\% & - & - & - & 0.8 & 0.2 \\
\hline
\end{tabular}

To perform the mortar-mixing, each material was first weighted on a balance with $0.1 \mathrm{~g}$ precision. Then, the constituents were placed in the previously moistened laboratory mixer. The container was attached to the mixer, which started working in automatic mode at a relatively slow speed. During the first $30 \mathrm{~s}$, and with the same movement, the water was poured into the container. After $2.5 \mathrm{~min}$, the mixer was stopped and the walls of the container were scraped off, so that all the material entered the mix. Finally, the mixer was switched on again, at the same speed, for another $30 \mathrm{~s}$.

The mortars were moulded in prismatic moulds with dimensions of $160 \mathrm{~mm} \times 40 \mathrm{~mm}$ $\times 40 \mathrm{~mm}$ (Figure 4) and maintained in controlled conditions until test. In the first 2 days, the mortars were kept at a temperature of $20 \pm 2{ }^{\circ} \mathrm{C}$ and a relative humidity of $95 \pm 5 \%$. Afterwards, the samples were demoulded and kept in the same conditions for 5 days. After this period, the relative humidity was reduced to $65 \pm 5 \%$ and the temperature remained constant.

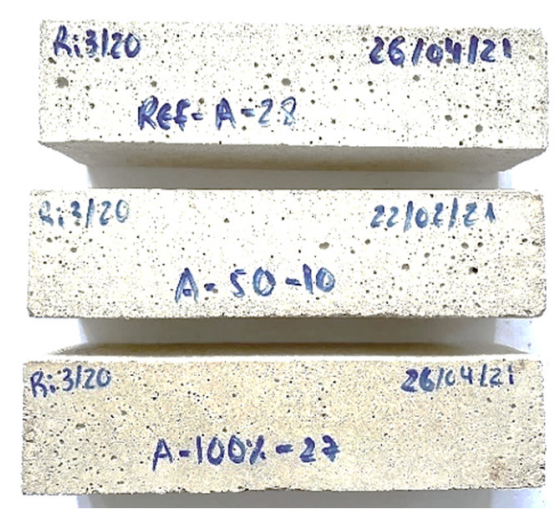

Figure 4. Mortars REF-A, A-50\% and A-100\% samples. 


\subsection{Methods}

The RA were analysed prior to their application in mortars. Along with the previously presented characterization of the CDW-A waste [10], three more tests were used for improved characterization and also to provide a comparison between non-carbonated and carbonated aggregates.

Therefore, the loose bulk density, particle density and water absorption of the aggregates were determined prior to and after carbonation for both $5 \mathrm{~h}$ and 5 days. The loose bulk density quantifies the dry mass of aggregate that is necessary to fill a container of known capacity, without compaction. The test procedure was carried out in accordance with the European standard EN 1097-3 [13]. Initially, the container of known capacity was placed at a well-defined distance under the conical-trunk mould that is plugged at the end of its base. Then, with the help of a trowel, the target material was placed in the conicaltruncated mould until it was filled. Attention should be paid to ensure that this placement is carried out with due care, so that the trowel does not touch the conical-truncated mould, avoiding any kind of compaction of the sample. Once the conical-truncated mould is full, the shutter is released in a single movement, allowing the sample, by the action of gravity, to fall onto the cylindrical container. The excess of material was then trimmed off using a spatula and the sample weighed on a balance with accuracy of $0.1 \mathrm{~g}$.

Particle density and water absorption were determined according to standard EN 1097-6 [14], with the same test protocol. The test protocol consists of weighting a sample of aggregate with approximately $100 \mathrm{~g}$, placing it in a pycnometer, and filling it with water until the sample is completely covered. Afterwards, the pycnometer was filled with water to a specific volume and the sample was held in a water bath at a temperature of $25.0 \pm 0.1^{\circ} \mathrm{C}$ for $60 \mathrm{~min}$.

The tests performed on mortars are presented in Table 2. The mortars' workability was analysed in terms of consistency by flow table test. This test consists of placing the fresh mortar into a truncated cone mould in two layers, each compacted with 10 short strokes. The mould is carefully removed, and 15 strokes are performed in the flow table at a rate of one stroke per second. Finally, the diameter of the mortar spread in two orthogonal directions is measured with a calliper. Each result of this test is given by the average of two perpendicular measurements performed on the mortar sample.

Table 2. Mortars characterization tests.

\begin{tabular}{ccc}
\hline Test & Ages Analysed (Days) & Standard \\
\hline Consistency by flow table & Fresh state & EN 1015-3 [15] \\
Bulk density & Fresh state & Cahier 2669-4 [16] \\
Bulk density & 14,28 & EN 1015-10 [17] \\
Modulus of elasticity by frequency of & 14,28 & EN 14146 [18] \\
resonance & 14,28 & EN 1015-11 [19] \\
Flexural strength & 14,28 & EN 1015-11 [19] \\
Compressive strength & 28 & EN 1015-18 [20] \\
\hline
\end{tabular}

The bulk density test in the fresh state consists of placing a fresh mortar inside a cylindric container, with a known volume, up to half its capacity. Then, it is compacted by oscillating the container in four alternate directions. Leaving the container supported on one side, the opposite side is lifted to a height of $3 \mathrm{~cm}$ and then left to fall. This is repeated for each of the remaining three directions. Then, the container is filled and compacted again in the same way. The excess mortar is removed by scraping the upper edge of the container with a trowel. Finally, the mortar and container are weighed. The result of this test consists of measuring the mass of a sample of this mix, for a given volume, with a given compaction. To measure the bulk density in the hardened state, a gauge was used to measure the length, height and width of each of the six specimens, and a precision balance 
of $0.001 \mathrm{~g}$ was used to measure the specimen mass. The density of the test specimens was calculated from these data.

To determine the dynamic modulus of elasticity, the frequency of resonance method was used, with the ZRM ZEUS 2005 equipment. This yields the fundamental resonance frequency of a material for an induced vibration in the longitudinal direction. This test was performed on six prismatic specimens. The modulus of elasticity, $M e,\left(\mathrm{~N} / \mathrm{mm}^{2}\right)$ can be calculated accounting for geometric data and the density of the hardened mortar, as per Equation (1):

$$
M e=(2 \times L \times f)^{2} \times \frac{\rho}{\mathrm{g}} \times 10^{-6}
$$

in which $L$ is the specimen length $(\mathrm{m}), f$ the longitudinal resonance frequency $(\mathrm{Hz}), \rho$ the density $\left(\mathrm{N} / \mathrm{mm}^{3}\right)$ and $\mathrm{g}$ the acceleration of gravity $\left(9.81 \mathrm{~m} / \mathrm{s}^{2}\right)$.

For the flexural strength test, the universal machine (ETI-HM-S/CPC from PROETI, S.A.) was prepared using a load cell of $2 \mathrm{kN}$, associated with the three-point bending device. The software program of the test equipment, which increments the load at a speed of $0.2 \mathrm{~mm} / \mathrm{min}$, was started, obtaining a graph of the applied force $(\mathrm{N})$ as a function of time (s), and the maximum applied force was registered. With half of each specimen resulting from the flexural tensile strength test, the compressive strength test was performed. Similarly, the equipment was prepared using the load cell of $200 \mathrm{kN}$ in the device for the compression of prisms with $40 \mathrm{~mm}$ of the section side. The values of the applied force were recorded as a function of time, as well as the maximum compressive force that occurs before failure. The compressive strength $\mathrm{Rc}_{\mathrm{c}}(\mathrm{MPa})$ is obtained through the quotient between the maximum force $(\mathrm{N})$ obtained by the equipment software and the load application section $\left(\mathrm{mm}^{2}\right)$.

Regarding water behaviour at 28 days, the water absorption curves and capillarity coefficients of the mortars were determined. This coefficient reflects the initial mortar's absorption speed. For this purpose, prismatic samples were cut in half and dried in a ventilated oven at $40 \pm 5{ }^{\circ} \mathrm{C}$ until constant mass was reached. Once dry, the samples were waterproofed on the four lateral faces with paraffin, thus guaranteeing that the absorption was unidirectional. The samples were placed in a container with water to a height of $1 \mathrm{~cm}$ above the immersed surface of the samples, as in Figure 5. The mass of the samples was weighed at 10, 30,60,90, 180, 480, $1400 \mathrm{~min}$ and every $24 \mathrm{~h}$ until saturation was reached. Thus, it was possible to obtain the capillarity coefficient through the slope of the first straight segment of the curve of water absorbed per area by the square root of time.

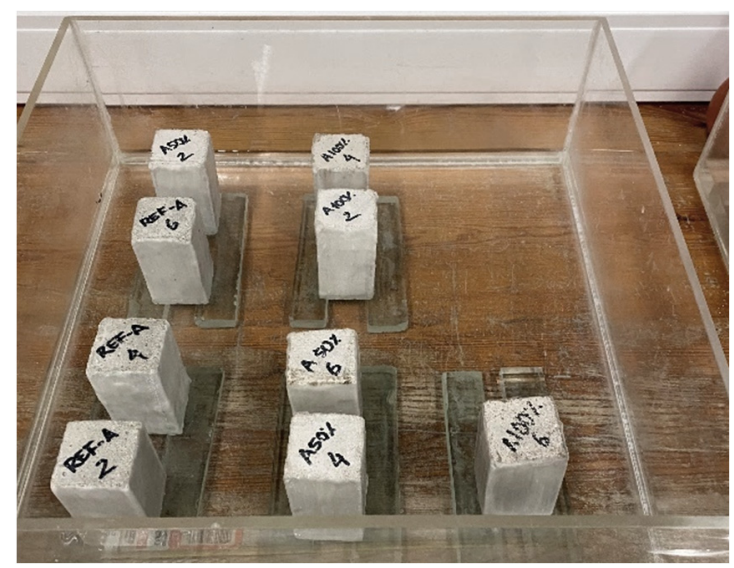

Figure 5. Water absorption by capillarity test.

\section{Results and Discussion}

\subsection{Recycled Aggregates}

RA from CDW were tested prior to forced/accelerated carbonation and immediately after, and the results are presented in Table 3. As expected, NA (sand) showed a considerably higher loose bulk density than that of the non-carbonated RA (CDW-A), mainly 
due to the greater porosity of the cementitious mortar that adhered to the RA's surface compared to NA's [21-24].

Table 3. Natural aggregates and recycled aggregates' physical properties.

\begin{tabular}{ccccc}
\hline Test & Sand & CDW-A & CDW-A-5h & CDW-A-5d \\
\hline Loose bulk density $\left(\mathrm{kg} / \mathrm{m}^{3}\right)$ & $1560 \pm 0.8$ & $1260 \pm 2.4$ & $1278 \pm 1.7$ & $1268 \pm 0.9$ \\
Particle density $\left(\mathrm{kg} / \mathrm{m}^{3}\right)$ & 2631 & 2212 & 2437 & 2551 \\
Water absorption $(\%)$ & 0.19 & 7.48 & 3.47 & 7.68 \\
\hline
\end{tabular}

The forced and accelerated carbonation of recycled aggregates is expected to improve their characteristics, namely, their loose bulk density and porosity [25]; thus, it can be used as a treatment. It should be noted that these improvements can play a fundamental role in the behaviour of the mortars in which they will be included. Carbonation improves the quality of the mortar that is adhered to the NA's surface [26,27] as, in this chemical reaction, $\mathrm{CO}_{2}$ reacts with calcium hydroxide to precipitate as $\mathrm{CaCO}_{3}$, filling its pores. Thus, the aggregates subjected to carbonation experience an increase in their bulk density and a consequent reduction in porosity $[5,28]$. This can be seen in the results obtained for the loose bulk density of carbonated aggregates (Table 3): there is an increase in the loose bulk density of carbonated recycled aggregates (CRA) for periods of $5 \mathrm{~h}$ and 5 days. However, it is noted that the forced carbonation of CDW-A RA for a relatively short period produced more significant improvements in the RA's loose bulk density than carbonation for longer periods. Nevertheless, increases in the particle density of these aggregates in accordance with the exposure time to high $\mathrm{CO}_{2}$ concentrations showed a different trend, and the exposure for 5 days $\left(2551 \mathrm{~kg} / \mathrm{m}^{3}\right)$ led to a higher value than exposure for $5 \mathrm{~h}$, which fell short of the particle density of NA $\left(2631 \mathrm{~kg} / \mathrm{m}^{3}\right)$.

The water absorption of aggregates is one of the main characteristics to account for when formulating mortars, as it greatly affects their workability [25]. Water absorption is expected to decrease with the exposure of aggregates to $\mathrm{CO}_{2}$. Naturally, this effect is closely linked to the increase in density and decrease in porosity. Table 4 shows a decrease of about $54 \%$ in the water absorption of carbonated RA for $5 \mathrm{~h}$, confirming an improvement in their properties. However, when exposed to $\mathrm{CO}_{2}$ for the longer period of 5 days, there is an increase in water absorption.

Table 4. Mortars' flow table consistency, water/binder ratio and bulk density.

\begin{tabular}{cccc}
\hline Mortar & Flow Table $(\mathbf{m m})$ & w/b Ratio & Bulk Density $\left(\mathbf{k g} / \mathbf{m}^{\mathbf{3}}\right)$ \\
\hline REF-A & 162 & 1.03 & $2060 \pm 14$ \\
A-50\% & 162 & 1.06 & $1972 \pm 7$ \\
AC-5h-50\% & 162 & 1.03 & $1983 \pm 15$ \\
AC-5d-50\% & 163 & 1.06 & $1964 \pm 12$ \\
A-100\% & 161 & 1.21 & $1917 \pm 15$ \\
AC-5h-100\% & 162 & 1.20 & $1900 \pm 14$ \\
AC-5d-100\% & 161 & 1.21 & $1919 \pm 10$ \\
\hline
\end{tabular}

Several authors have recorded improvements in the water absorption of RA subjected to forced carbonation. In these studies, several carbonation periods were defined. Gholizadeh-Vayghan et al. [29] carbonated crushed concrete specimens for $1 \mathrm{~h}$ and $24 \mathrm{~h}$, obtaining reductions in water absorption of $5 \%$ and $28 \%$, respectively. Other author studied the carbonation effect of crushed old mortars for different periods $(6 \mathrm{~h}, 12 \mathrm{~h}, 24 \mathrm{~h}, 48 \mathrm{~h}$ and $72 \mathrm{~h}$ ), with reductions of $13 \%, 40 \%, 62 \%, 65 \%$ and $68 \%$, respectively [28]. Extended periods of 3 and 7 days were studied by Shi et al. [30] and Abate et al. [31], respectively, resulting in decreases in water absorption of $36 \%$ and $7 \%$. Hence, the literature shows a decrease in CRA water absorption regardless of the periods used. However, for long periods (7 days), this decrease is much lower $(7 \%)$. However, it must be noted that the results found in the literature use different materials, with several backgrounds, and $\mathrm{CO}_{2}$-curing methods, 
and thus obtain different trends regarding the carbonation period and water absorption decrease. Conversely, in the current study, as stated, an unexpected increase was found in the water absorption of CDA-A subjected to forced carbonation for 5 days. Thus, the forced and accelerated carbonation of RA for long periods may have adverse effect on their properties and, consequently, on the physical and mechanical properties of mortars. Nevertheless, this phenomenon is being studied to obtain a better understanding of the reactions and products that result from extended carbonation periods.

\subsection{Mortars}

\subsubsection{Fresh-State Properties}

In non-structural mortars, such as renders, the water/binder $(\mathrm{w} / \mathrm{b})$ ratio is defined by accounting for the proper workability of the mortars. The results obtained for mortar consistency in terms of flow table (workability), bulk density and $\mathrm{w} / \mathrm{b}$ ratio, are presented in Table 4 . The flow value for the adequate workability of the mortars produced for this study was set at $162 \pm 1 \mathrm{~mm}$, as this was found by trial applications to be the most adequate for their application as renders or plasters.

An increase in the $\mathrm{w} / \mathrm{b}$ ratio was observed with the incorporation of $\mathrm{CDW}-\mathrm{A}$, i.e., the use of RA in the mortar causes the increase in the water that is required to achieve the defined flow value [32]. This tendency is in accordance with the water absorption values of NA and RA (Table 1). A-100\% mortar, formulated with $100 \%$ of RA without any treatment, has a $\mathrm{w} / \mathrm{b}$ ratio that is about $17.5 \%$ higher than that of the reference mortar. As stated, carbonation has a positive impact on the decrease in RA's water absorption and its increase in compacity. Therefore, a similar trend is expected in relation to the $\mathrm{w} / \mathrm{b}$ ratio [25]. This trend can be seen in mortars with a $50 \%$ replacement of NA with CRA-5h, in which the $\mathrm{w} / \mathrm{b}$ is equal to that of REF-A (1.03), as opposed to the mortars with $50 \%$ of CRA-5d. When NA is completely replaced with RA, aggregate exposed to high $\mathrm{CO}_{2}$ concentrations for $5 \mathrm{~h}$ are shown to have a decrease in $\mathrm{w} / \mathrm{b}$ ratio, while this ratio remains unchanged under exposure for 5 days. These results are promising in terms of the amount of mixing water required for mortars with CRA.

Regarding the mortars' bulk density in the fresh state, REF-A presents the highest value, of about $2060 \pm 14 \mathrm{~kg} / \mathrm{m}^{3}$. In general, the bulk density of mortars decreases with the increase in RA incorporation, either as such or subjected to $\mathrm{CO}_{2}$ curing.

\subsubsection{Hardened State \\ Bulk Density}

The average of three measurements of bulk density in the hardened state, at 14 and 28 days, for each produced mortar, is seen in Table 5. It is observed that the bulk density of hardened specimens decreases with the amount of CDW that is incorporated. This reduction, probably due to the lower particle density of the CDW compared with the natural sand, is low, and corresponds to $2 \%$ in the case of A-50\% and $4 \%$ in the case of A- $100 \%$. Contrary to what is described in the literature, the forced carbonation of RA does not have a significant impact on the mortars' apparent bulk density.

Table 5. Bulk density in the hardened state at 14 and 28 days.

\begin{tabular}{ccc}
\hline \multirow{2}{*}{ Mortar } & \multicolumn{2}{c}{ Bulk Density $\mathbf{( k g / \mathbf { m } ^ { 3 } )}$} \\
\cline { 2 - 3 } & 14 Days & 28 Days \\
\hline REF-A & $1933 \pm 70$ & $1942 \pm 4$ \\
A-50\% & $1902 \pm 15$ & $1886 \pm 4$ \\
AC-5h-50\% & $1845 \pm 3$ & $1838 \pm 10$ \\
AC-5d-50\% & $1900 \pm 14$ & $1865 \pm 11$ \\
A-100\% & $1851 \pm 50$ & $1771 \pm 10$ \\
AC-5h-100\% & $1807 \pm 7$ & $1768 \pm 15$ \\
AC-5d-100\% & $1796 \pm 16$ & $1802 \pm 14$ \\
\hline
\end{tabular}


Modulus of Elasticity by Frequency of Resonance

In Figure 6, the modulus of elasticity by frequency of resonance of the mortars is illustrated. As expected, the modulus of elasticity is greater for the reference mortar (REFA) and decreases with the increase in the amount of CDW-A incorporated in the mortar. The mortars with $50 \%$ of CDW-A (non-carbonated) waste have an elasticity modulus of about $12 \mathrm{GPa}$, which corresponds at 28 days to a decrease of $22 \%$ in comparison with REF-A. The mortar with $100 \%$ of waste presents a modulus of elasticity of about $9 \mathrm{GPa}$, little more than half of the reference mortar. Comparing the carbonated and not-carbonated aggregates, a slight decrease is noticed, with the exception of mortars with CRA-5h at 14 days, which do not show significant differences.

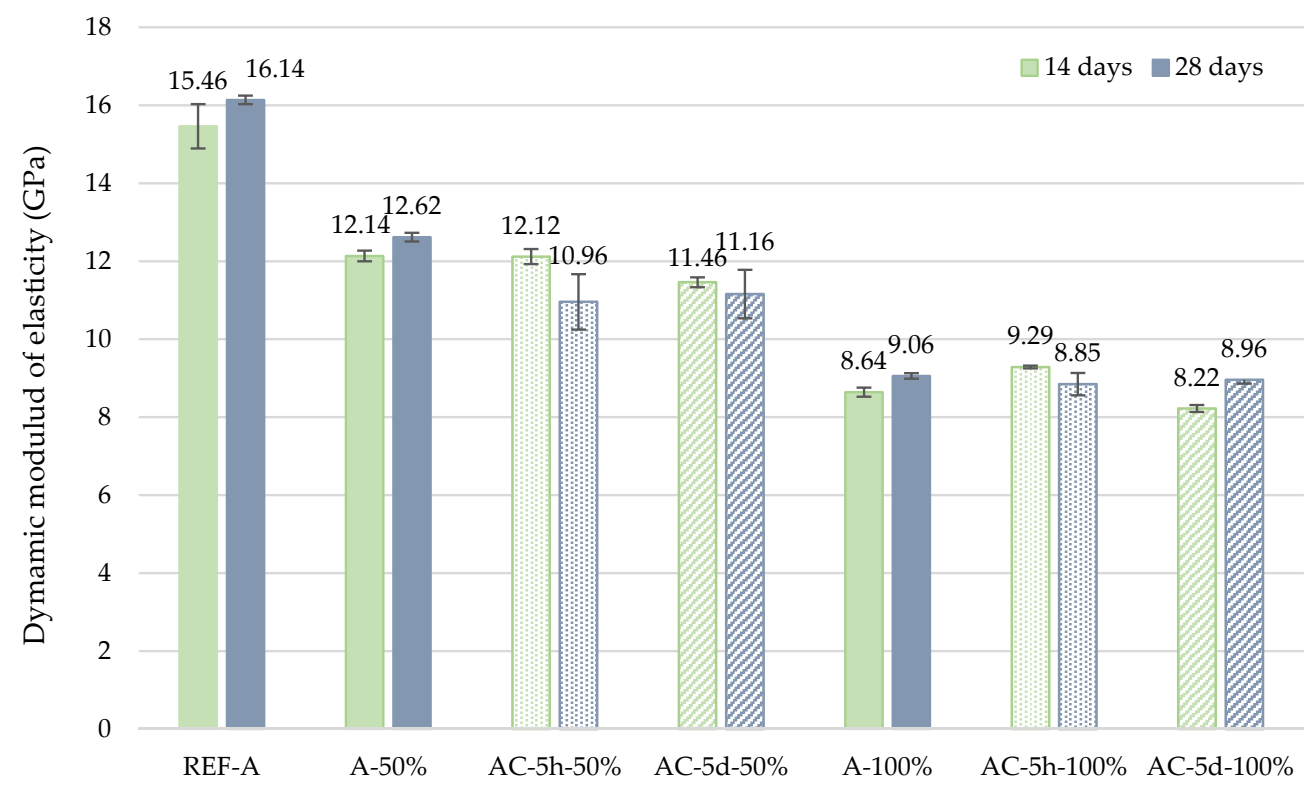

Figure 6. Dynamic modulus of elasticity results.

It is possible to observe a small decrease in the dynamic modulus of elasticity of mortars AC- 5 h- $50 \%$, AC- $5 \mathrm{~d}-50 \%$ and AC- $5 \mathrm{~h}-100 \%$, from 14 to 28 days. This may be due to the high level of waste incorporation, which leads to internal micro-cracking and reduces the stiffness of the mortars [33].

\section{Flexural Strength}

Mortars formulated with $50 \%$ non-carbonated RA do not show a significant decrease in flexural strength, both at 14 and 28 days (Figure 7). However, a decrease is noticed for mortars with $100 \%$ non-carbonated RA. For RA that is carbonated over $5 \mathrm{~h}$, there are small increases in flexural strength compared to non-carbonated RA, except for the 50\% substitution at 28 days (AC-5h-50\%). Finally, for RA carbonated for 5 days, there are decreases in flexural strength, which are especially significant for the $100 \%$ replacement (AC-5d-100\%).

Mortars with aggregates that are carbonated for 5 days show contradictory results, both with those obtained in this study and those in the literature [30-32]. However, it can be stated that, in terms of flexural strength, mortars with RA that are subjected to carbonation with high levels of $\mathrm{CO}_{2}$ for a long period are negatively affected, while, when exposed for short periods, a positive trend is noticed. 


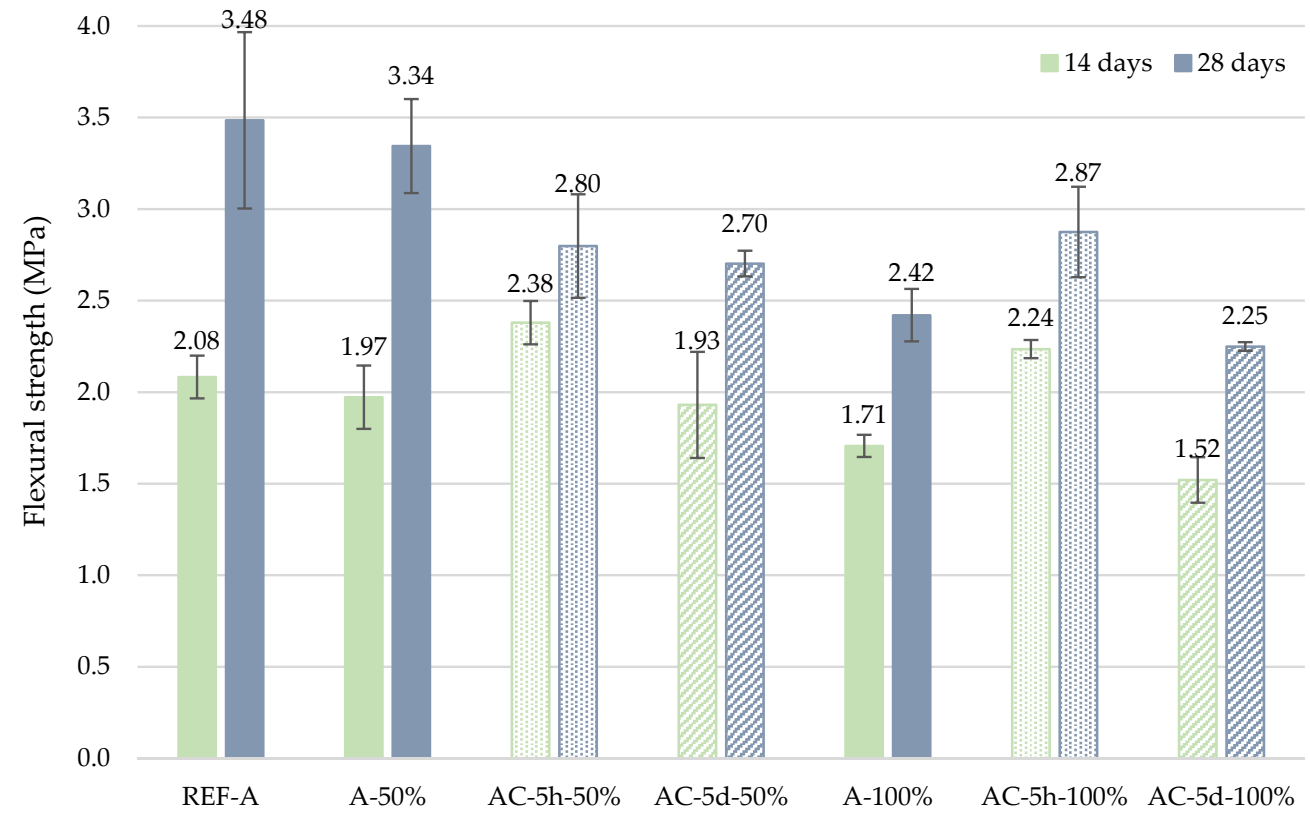

Figure 7. Flexural strength results.

\section{Compressive Strength}

The results of the compressive strength test, presented in Figure 8, show the same trend as the flexural strength results. Concerning the non-carbonated aggregates, a decrease in strength is noticed only for a 100\% replacement compared with the control mortar. After carbonation for $5 \mathrm{~h}$, an improvement in strength is obtained at 14 days, for both for $50 \%$ and $100 \%$ replacement, proving the effectiveness of $\mathrm{CO}_{2}$ curing in increasing the compressive strength of mortars [25]. However, at 28 days, small decreases occur by comparison with the non-carbonated RA (12\% and $1 \%$ for $50 \%$ and $100 \%$ substitution, respectively). Finally, after 5 days of carbonation, decreases are generally seen compared with the non-carbonated RA, except in the case of AC-5d-100\% at 14 days, which shows a higher compressive strength than $\mathrm{A}-100 \%$ at the same age.

Similar to what was found in the flexural strength results, the compressive strengths of these mortars are high when compared to the usual non-structural mortars. The grain size distribution of the waste could be responsible for these strengths due to the high content of fine particles; a large amount of fines can play an important role in the increase in the mortars' strength though improvements in its compactness due to the filler effect (fulfilment of some pores) [33,34].

\section{Water Absorption by Capillarity}

In general, mortars produced with CDW-A show a slower water absorption than REFA, illustrated by a lower capillarity water absorption coefficient (Table 6). This decrease in water absorption in accordance with capillarity rate in the first minutes may indicate that the capillary pore diameter is smaller in the recycled mortars [35]. 


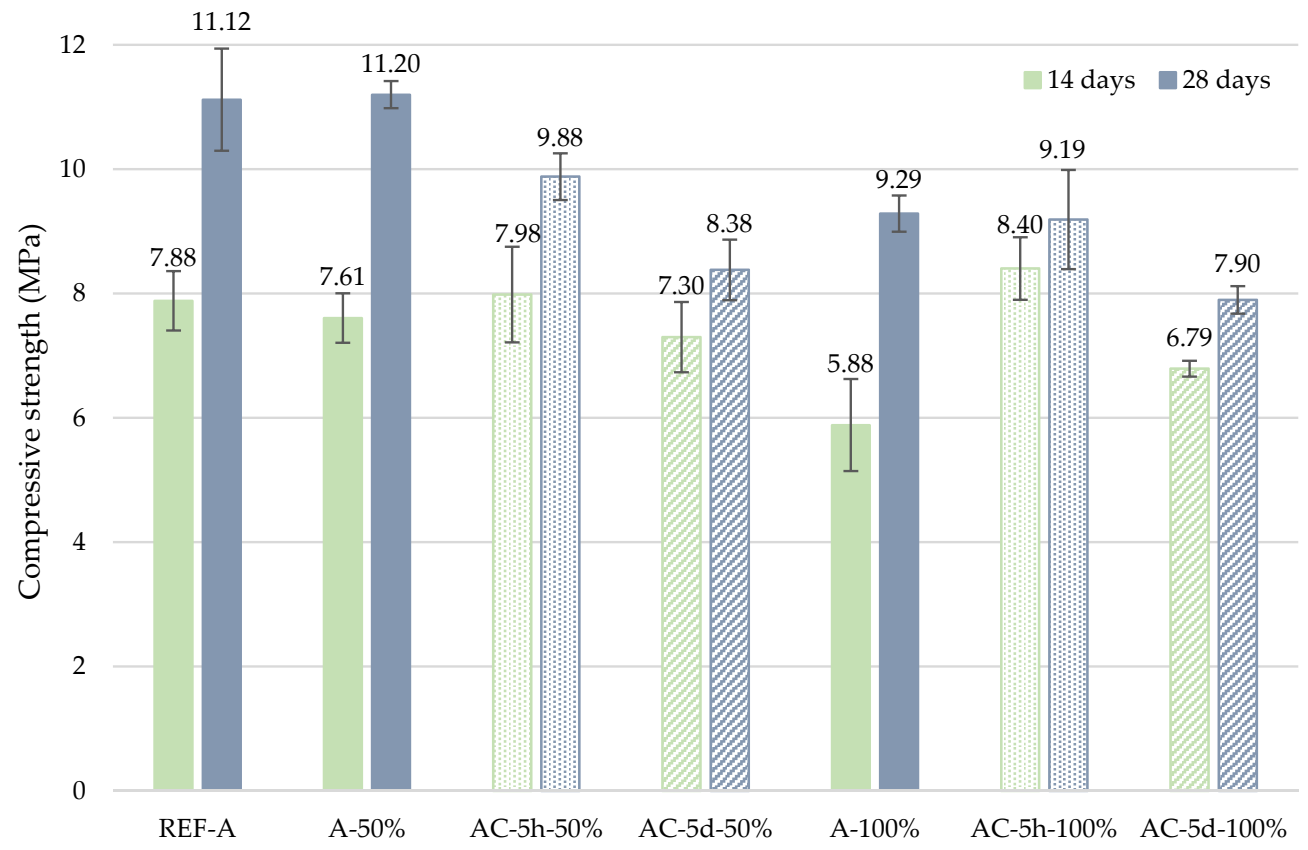

Figure 8. Compressive strength results.

Table 6. Capillary coefficient of mortars incorporating CDW-A.

\begin{tabular}{cc}
\hline Mortar & Capillary Coefficient $\left(\mathbf{k g} /\left(\mathbf{m}^{\mathbf{2}} \cdot \mathbf{m i n}^{\mathbf{1 / 2}}\right)\right)$ \\
\hline REF-A & $0.81 \pm 0.03$ \\
A-50\% & $064 \pm 0.04$ \\
AC-5h-50\% & $0.55 \pm 0.01$ \\
AC-5d-50\% & $0.76 \pm 0.04$ \\
A-100\% & $0.72 \pm 0.04$ \\
AC-5h-100\% & $0.67 \pm 0.01$ \\
AC-5d-100\% & $0.82 \pm 0.03$ \\
\hline
\end{tabular}

Carbonation of RA for $5 \mathrm{~h}$ produces a decrease in the capillary coefficients of mortars for both $50 \%$ and $100 \%$ replacement, by comparison with non-carbonated RA mortars. However, a long period of carbonation increases the capillary water absorption coefficient compared to the non-carbonated mortars. AC-5d-100\% presents a similar capillarity coefficient to the reference, of around $0.80 \mathrm{~kg} /\left(\mathrm{m}^{2} \cdot \mathrm{min}^{1 / 2}\right)$. Zhang et al. [9] stated that mortars with CRA show a slight decrease in water absorption compared to those with $\mathrm{RA}$, leading to a positive influence of the aggregates' $\mathrm{CO}_{2}$ curing on mortar porosity. Both AC-5h-50\% and AC-5h-100\% have considerably lower capillary coefficients, consistent with the low porosity shown by the previous results of the aggregates' characterization [10]. Mortars with aggregates carbonated for $5 \mathrm{~h}$ show results in accordance with those found in the literature $[9,29]$, while for mortars with aggregates exposed to longer carbonation periods, the results are the opposite.

Nevertheless, analysing the absorption curves (Figure 9), mortars with RA absorb a greater volume of water over time than the reference mortar, owing to the higher volume of capillary pores. It is also noticed that mortars with $100 \%$ RA, both carbonated and non-carbonated, present a greater volume of absorbed water when compared with the $50 \%$ replacement mortars. Carbonation of the aggregates influences the maximum water absorption in a similar way as the capillary coefficient: carbonation for $5 \mathrm{~h}$ reduces the water absorption over time, while a long period of carbonation leads to maximum values of water absorption similar to or a little higher than non-carbonated RA. 


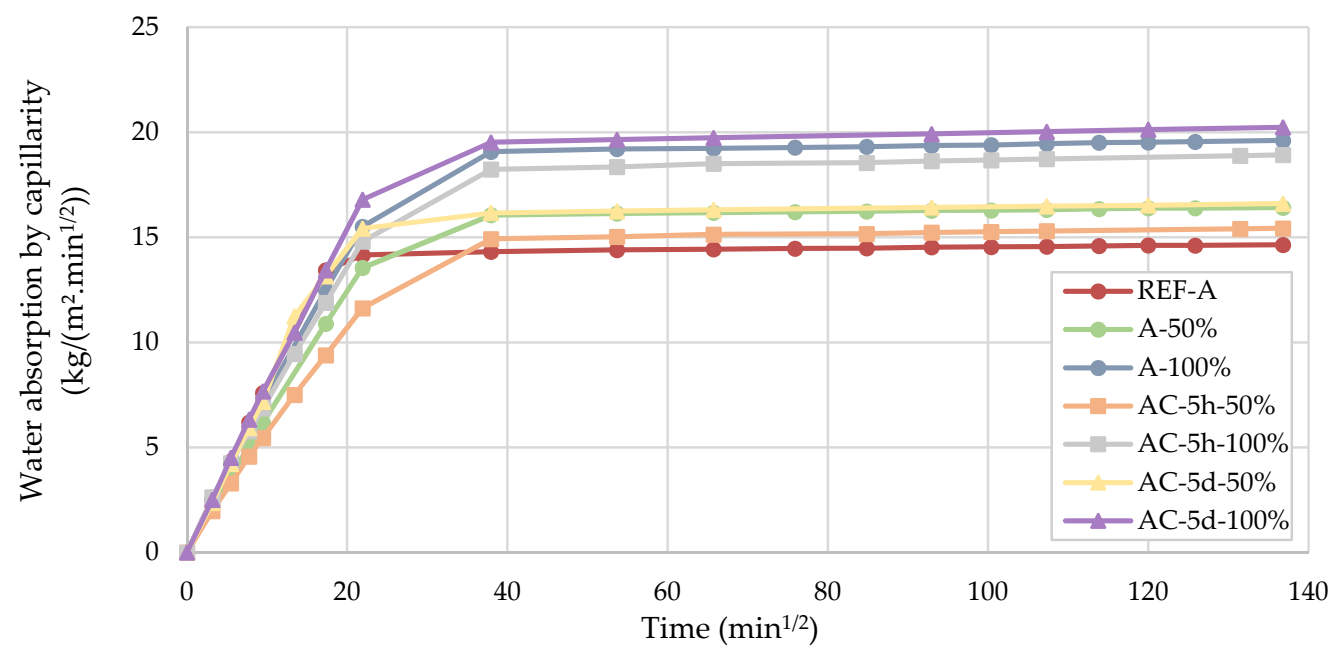

Figure 9. Capillarity water absorption curves.

\section{Conclusions}

A CDW commercialised by a Portuguese recycling plant was incorporated in cementitious non-structural mortars, replacing sand at 50\% and $100 \%$. The obtained results indicate that the replacement is viable and the mortars with less content or without sand present a good performance in both fresh and hardened states for the intended uses.

Mortars with the same recycled aggregates (RA) submitted to forced and accelerated carbonation for a short and a long period of $5 \mathrm{~h}$ and 5 days, respectively, were also analysed in terms of the needs of mixing water to achieve a fixed consistency according to flow table, and bulk density in the fresh state, as well as being analysed in terms of their bulk density, mechanical behaviour and water absorption by capillarity in the hardened state. Non-carbonated and carbonated aggregates were also evaluated in terms of their loose bulk density, particle density and water absorption.

Forced and accelerated carbonation acted as a pre-treatment to the RA and should lead to an increase in its particle density and a consequent decrease in porosity. The results confirmed the increase in RA particle density on the exposure to high levels of $\mathrm{CO}_{2}$ (25\%). However, the loose bulk density of these aggregates showed a more significant increase after carbonation for $5 \mathrm{~h}$ (CRA-5h), from $1260 \pm 2.4$ to $1278 \pm 1.7 \mathrm{~kg} / \mathrm{m}^{3}$, as opposed to carbonation for 5 days (CRA-5D), after which a slight increase was found $\left(1268 \pm 0.9 \mathrm{~kg} / \mathrm{m}^{3}\right)$. Regarding water absorption, a 54\% decrease was registered for CRA$5 \mathrm{~h}$ compared to non-carbonated RA. It should be noticed that CRA-5d aggregates showed an increase in water absorption, which may indicate that extensive periods of carbonation could negatively influence the aggregates.

The incorporation of CDW-A in cementitious mortars caused an increase in the $\mathrm{w} / \mathrm{b}$ ratio, which was higher when NA was replaced with RA. However, mortars produced with aggregates that were carbonated for a short time, CRA-5h did not undergo changes in the $\mathrm{w} / \mathrm{b}$ ratio, unlike those produced with ones carbonated for a long time, CRA-5d.

The incorporation of RA affected the mortars' mechanical behaviour, especially in the case of a $100 \%$ replacement of NA. The flexural and compressive strength of mortars with non-carbonated RA showed a decrease after $100 \%$ replacement, and in the case of the dynamic modulus of elasticity, a decrease after $50 \%$ replacement. The mortars with CRA-5h showed a trend for slight increase in the mechanical properties. On the other hand, the mortars that incorporate CRA over a longer carbonation period evidenced decreases in mechanical values, in comparison with non-carbonated RA.

The capillary water absorption coefficient of the mortars decreased when NA was substituted with RA, especially in the case of $50 \%$ replacement. This decrease was even more noticeable for mortars with aggregates that were exposed to $5 \mathrm{~h}$ of carbonation. However, for mortars that were carbonated for 5 days, CRA- $5 \mathrm{~d}$, the capillary coefficient increased again and was similar to that of the REF mortars. Concerning water absorption 
in the long term, it was found that mortars with RA showed higher maximum water absorption than the REF mortar, and, again, $5 \mathrm{~h}$ carbonation reduced absorption while $5 \mathrm{~d}$ carbonation tended to increase the maximum absorption.

These results seem to point out that the RA used was densified by carbonation over $5 \mathrm{~h}$, resulting in improved characteristics of the mortars in which they were incorporated. In general, slightly higher mechanical characteristics and lower water absorption values were obtained by comparison with mortars with non-carbonated RA. However, longer periods of carbonation reduce the quality of the RA and, as a consequence, the mechanical and hydric characteristics of the mortars were negatively affected. Nonetheless, it must be stressed that the characteristics obtained for mortars with RA, both non-carbonated and carbonated, seem adequate for use in non-structural mortars, for example, as renders and plasters.

From the results, it can be stated that RA can be positively affected by a $\mathrm{CO}_{2}$ curing for short periods. Hence, this pre-treatment can enhance the RA properties and, at the same time, capture and store $\mathrm{CO}_{2}$, which has very important environmental benefits.

Author Contributions: R.I.G. and D.B. performed all the tests. R.I.G., C.B.F. and C.M.P. established the correlation between all tests results. R.V., J.d.B., P.F. and A.S.S. supervised the research. R.I.G. wrote the manuscript. C.B.F., C.M.P., R.V., J.d.B., P.F. and A.S.S. revised the manuscript. All authors have read and agreed to the published version of the manuscript.

Funding: This research was funded within the research project WP10B by c ${ }^{5} \mathrm{Lab}$ (CoLab 4/2018CemLab).

Data Availability Statement: The data presented in this study are available on request from the corresponding author.

Acknowledgments: The authors acknowledge to the c5Lab-Sustainable Construction Materials, the National Laboratory for Civil Engineering (LNEC), and the research unit CERIS from Instituto Superior Técnico (IST) for the support given to this research.

Conflicts of Interest: The authors declare no conflict of interest.

\section{References}

1. Sanjuán, M.Á.; Andrade, C.; Mora, P.; Zaragoza, A. Carbon dioxide uptake by mortars and concretes made with Portuguese cements. Appl. Sci. 2020, 10, 646. [CrossRef]

2. Directorate-General for Environment (European Commission). EU Construction E Demolition Waste Management Protocol; European Commission: Brussels, Belgium, 2016; pp. 1-22. [CrossRef]

3. CEMBUREAU. The Role of Cement in the 2050 Low Carbon Economy; The European Cement Association: Brussels, Belgium, 2013.

4. Morandeau, A.; Thiéry, M.; Dangla, P. Investigation of the carbonation mechanism of CH and C-S-H in terms of kinetic microstructure changes and moisture properties. Cem. Concr. Res. 2014, 56, 153-170. [CrossRef]

5. Zhan, B.; Poon, C.S.; Liu, Q.; Kou, S.; Shi, C. Experimental study on $\mathrm{CO}_{2}$ curing for enhancement of recycled aggregate properties. Constr. Build. Mater. 2014, 67, 3-7. [CrossRef]

6. Zhan, B.J.; Yang, K.H.; Seo, E.A.; Tae, S.H. Carbonation and $\mathrm{CO}_{2}$ uptake of concrete. Constr. Build. Mater. 2020, 67, 7880-7887. [CrossRef]

7. Pade, C.; Guimaraes, M. The $\mathrm{CO}_{2}$ uptake of concrete in a 100 year perspective. Cem. Concr. Res. 2007, 37, 1348-1356. [CrossRef]

8. Zhang, J.; Shi, C.; Li, Y.; Pan, X.; Poon, C.S.; Xie, Z. Influence of carbonated recycled concrete aggregate on properties of cement mortar. Constr. Build. Mater. 2015, 98,1-7. [CrossRef]

9. Li, L.; Xiao, J.; Xuan, D.; Poon, C.S. Effect of carbonation of modeled recycled coarse aggregate on the mechanical properties of modeled recycled aggregate concrete. Cem. Concr. Compos. 2018, 89, 169-180. [CrossRef]

10. Gomes, R.I.; Bastos, D.; Farinha, C.; Veiga, R.; de Brito, J.; Faria, P.; Silva, A.S.; Bogas, A. Carbonation potential of recycled aggregates from construction and demolition waste. In Proceedings of the 2021 fib Symposium, Lisbon, Portugal, 14-16 June 2021; pp. 825-832, ISBN 978-2-940643-08-0.

11. EN 933-11. Tests for Geometrical Properties of Aggregates. Part 11: Classification Test for the Constituents of Coarse Recycled Aggregate; European Committee for Standardization (CEN): Brussels, Belgium, 2009.

12. EN 13242. Aggregates for Unbound and Hydraulically Bound Materials for Use in Civil Engineering Work and Road Construction; European Committee for Standardization (CEN): Brussels, Belgium, 2007.

13. EN 1097-3. Tests for Geometrical Properties of Aggregates-Part 3: Determination of Loose Bulk Density and Voids; European Committee for Standardization (CEN): Brussels, Belgium, 1998. 
14. EN 1097-6. Tests for Mechanical and Physical Properties of Aggregates-Part 6: Determination of Particle Density and Water Absorption; European Committee for Standardization (CEN): Brussels, Belgium, 2003.

15. EN 1015-3. Methods of Test for Mortar for Masonry-Part 3: Determination of Consistence of Fresh Mortar (by Flow Table); European Committee for Standardization (CEN): Brussels, Belgium, 1999.

16. Cahier 2669-4. Certification CSTB des Enduits Monocouches d'imperméabilisation, Modalités d'essais; CSTB: Marne la Vallée, France, 1993.

17. EN 1015-10. Methods of Test for Mortar for Masonry-Part 10: Determination of Dry Bulk Density of Hardened Mortar; European Committee for Standardization (CEN): Brussels, Belgium, 1999.

18. EN 14146. Natural Stone Tests Methods: Determination of the Dynamic Modulus of Elasticity (by Measuring the Fundamental Resonance Frequency); European Committee for Standardization (CEN): Brussels, Belgium, 2004.

19. EN 1015-11. Methods of Test for Mortar for Masonry-Part 11: Determination of Flexural and Compressive Strength of Hardened Mortar; European Committee for Standardization (CEN): Brussels, Belgium, 1999.

20. EN 1015-18. Methods of Test for Mortar for Masonry-Part 18: Determination of Water Absorption Coefficient due to Capillary Action of Hardened Mortar; European Committee for Standardization (CEN): Brussels, Belgium, 2002.

21. De Brito, J.; Agrela, F.; Silva, R.V. Construction and demolition waste. In New Trends in Eco-efficient and Recycled Concrete; Elsevier: Amsterdam, The Netherlands, 2019; pp. 1-22.

22. Jiménez, J.R.; Ayuso, J.; López, M.; Fernández, J.M.; de Brito, J. Use of fine recycled aggregates from ceramic waste in masonry mortar manufacturing. Constr. Build. Mater. 2013, 40, 679-690. [CrossRef]

23. Tabsh, S.W.; Abdelfatah, A.S. Influence of recycled concrete aggregates on strength properties of concrete. Constr. Build. Mater. 2009, 23, 1163-1167. [CrossRef]

24. Wu, J.; Zhang, Y.; Zhu, P.; Feng, J.; Hu, K. Mechanical Properties and ITZ Microstructure of Recycled Aggregate Concrete Using Carbonated Recycled Coarse Aggregate. J. Wuhan Univ. Technol. Mater. Sci. Ed. 2018, 33, 648-653. [CrossRef]

25. Gomes, R.I.; Farinha, C.B.; Veiga, R.; de Brito, J.; Faria, P.; Bastos, D. $\mathrm{CO}_{2}$ sequestration by construction and demolition waste aggregates and effect on mortars and concrete performance-An overview. Renew. Sustain. Energy Rev. 2021, 152, 111668. [CrossRef]

26. Lu, B.; Shi, C.; Cao, Z.; Guo, M.; Zheng, J. Effect of carbonated coarse recycled concrete aggregate on the properties and microstructure of recycled concrete. J. Clean. Prod. 2019, 233, 421-428. [CrossRef]

27. Luo, S.; Ye, S.; Xiao, J.; Zheng, J.; Zhu, Y. Carbonated recycled coarse aggregate and uniaxial compressive stress-strain relation of recycled aggregate concrete. Constr. Build. Mater. 2018, 188, 956-965. [CrossRef]

28. Kou, S.C.; Zhan, B.J.; Poon, C.S. Use of a $\mathrm{CO}_{2}$ curing step to improve the properties of concrete prepared with recycled aggregates. Cem. Concr. Compos. 2014, 45, 22-28. [CrossRef]

29. Gholizadeh-Vayghan, A.; Bellinkx, A.; Snellings, R.; Vandoren, B.; Quaghebeur, M. The effects of carbonation conditions on the physical and microstructural properties of recycled concrete coarse aggregates. Constr. Build. Mater. 2020, 257, 119486. [CrossRef]

30. Shi, C.; Wu, Z.; Cao, Z.; Ling, T.C.; Zheng, J. Performance of mortar prepared with recycled concrete aggregate enhanced by $\mathrm{CO}_{2}$ and pozzolan slurry. Cem. Concr. Compos. 2018, 86, 130-138. [CrossRef]

31. Abate, S.Y.; Song, K.I.; Song, J.K.; Lee, B.Y.; Kim, H.K. Internal curing effect of raw and carbonated recycled aggregate on the properties of high-strength slag-cement mortar. Constr. Build. Mater. 2018, 165, 64-71. [CrossRef]

32. Muñoz, A.; Torres, N.; Guzmán, A. Evaluación de un mortero preparado con agregados reciclados de un concreto mejorado por carbonatación: Una mirada a la construcción sustentable Assessment of a mortar with recycled aggregate from a concrete improved by carbonation: A look to a sustainable. Rev. Ing. Constr. 2019, 34, 25-32. Available online: www.ricuc.cl (accessed on 22 June 2021). [CrossRef]

33. Farinha, C.B.; de Brito, J.; Veiga, R. Incorporation of fine sanitary ware aggregates in coating mortars. Constr. Build. Mater. 2015, 83, 194-206. [CrossRef]

34. Westerholm, M.; Lagerblad, B.; Silfwerbrand, J.; Forssberg, E. Influence of fine aggregate characteristics on the rheological properties of mortars. Cem. Concr. Compos. 2008, 30, 274-282. [CrossRef]

35. Santos, A.R.; Veiga, M.D.R.; Silva, A.S.; de Brito, J.; Álvarez, J.I. Evolution of the microstructure of lime based mortars and influence on the mechanical behaviour: The role of the aggregates. Constr. Build. Mater. 2018, 187, 907-922. [CrossRef] 